\title{
O princípio da eficiência e a (i)legitimidade do controle jurisdicional das políticas públicas
}

\author{
The efficiency principle and the (i)legitimacy of jurisdictional control of the \\ public policies
}

\author{
Ilton Garcia da Costa \\ Universidade Estadual do Norte do Paraná - UENP \\ Doutor em Direito \\ Professor do Programa de Doutorado, Mestrado e Graduação da UENP \\ São Paulo/SP, Brasil \\ iltongcosta@gmail.com
}

Ana Flávia Coelho dos Santos

Universidade Estadual do Norte do Paraná - UENP

Mestra em Ciência Jurídica

Advogada

Andirá/PR, Brasil

anaflaviacsantos@outlook.com

Resumo: A eficiência foi acrescentada no art. 37, caput, da Constituição Federal passando, pois, a integrar o rol dos princípios gerais administrativos no final da década de noventa com a Reforma Administrativa, embora sempre ressaltada pela doutrina e jurisprudência como um requisito imprescindível dos atos administrativos. A Emenda Constitucional 19/98 foi a responsável por integrar de maneira expressa o princípio da eficiência no ordenamento jurídico pátrio favorecendo o seu amplo conhecimento à comunidade de modo a possibilitar a exigência e o controle de resultados da atuação estatal. Entretanto, identifica-se constante inobservância deste princípio pelos agentes públicos e, consequentemente, a atuação atípica dos outros Poderes, o que repercute na questão do sistema de freios e contrapesos. Sob essa perspectiva, este artigo objetiva discorrer sobre a legitimidade do controle jurisdicional das políticas públicas quando da inobservância do princípio da eficiência pela Administração Pública. O trabalho adota o método de pesquisa dedutivo e utiliza a pesquisa bibliográfica como procedimento técnico, pautado, majoritariamente, na análise de artigos publicados em periódicos e na consulta à legislação.

Palavras-chave: princípio da eficiência; administração pública; políticas públicas; reforma administrativa; controle jurisdicional.

Abstract: The efficiency was added in art. 37, caput, of the Federal Constitution and therefore became part of the list of general administrative principles in the late nineties with the Administrative Reform, but it has always been highlighted by doctrine and jurisprudence as an essential principle of administrative acts. The Constitutional Amendment 19/98 was responsible for expressly integrating the principle of efficiency in the national legal system, favoring its wide knowledge to the community to enable the demand and control of the results of the state action. However, there is constant non-compliance with this principle by public agents and, 
consequently, the atypical performance of other Powers, which affects the issue of checks and balances. From this perspective, this article aims to discuss the legitimacy of jurisdictional control of public policies when the principle of efficiency is not respected by the Public Administration. The article adopts the deductive research method and uses bibliographic research as a technical procedure, based mostly on the analysis of articles published in journals and on consulting the legislation.

Keywords: principle of efficiency; public administration; public policies; administrative reform; jurisdictional control.

\section{Para citar este artigo}

ABNT NBR 6023:2018

COSTA, Ilton Garcia da; SANTOS, Ana Flávia Coelho dos. O princípio da eficiência e a (i)legitimidade do controle jurisdicional das políticas públicas. Prisma Jurídico, São Paulo, v. 20, n. 2, p. 311-329, jul./dez. 2021. http://doi.org/10.5585/prismaj.v20n2.20145.

\section{Introdução}

Integrante do rol do art. 37, caput, da Constituição Federal de 1988, que estabelece os princípios constitucionais da Administração Pública, a eficiência corresponde a um dos valores fundamentais que sistematiza o Direito Administrativo brasileiro. A doutrina faz referência aos princípios como sendo o alicerce de um sistema, defendido, inclusive, por alguns doutrinadores, como pertencentes a um escalão mais elevado do que as normas regras. Vale lembrar que o Direito Administrativo no Brasil não é codificado, por esse motivo os princípios que regem a matéria ganham ainda mais destaque.

O dever de observância a esses princípios gerais expressos no art. 37, caput, bem como a todos os outros espalhados pela CF/1988, é cogente. Todavia, se verifica certa mitigação a esses princípios, para não dizer negligência, por parte dos agentes públicos quando do desempenho de suas funções, gerando para a coletividade o descontentamento dos resultados do serviço público desempenhado.

Neste contexto de não satisfação dos anseios sociais, o Poder Judiciário sob a égide do Neoconstitucionalismo, que lhe atribui a função de guardião da Constituição, e, principalmente, dos direitos fundamentais, não raramente vem desempenhando funções atípicas, que despertam resistência do Poder Executivo e de quem considera esta interferência jurisdicional ilegítima. Dessa "interferência” jurisdicional em questões de competência típica dos outros Poderes surte uma gama de discussões envolvendo assuntos mais profundos como o pós-positivismo, por exemplo, marco filosófico do Neoconstitucionalismo, que atribui a centralidade do sistema na 
Dignidade da Pessoa Humana e reconhece a imperatividade das normas constitucionais, sejam regras ou princípios.

Há quem rechace o controle jurisdicional, sob o argumento de não deferência entre os Poderes, que resulta na violação da consagrada Teoria da Separação dos Poderes de Montesquieu. Na esteira desse discurso, haveria uma tendência contemporânea de apostar no protagonismo judicial para a busca da concretização de direitos. Isso decorreria de uma equivocada recepção da chamada Jurisprudência dos Valores. Critica-se justamente o Ativismo Judicial e o excesso de discricionariedade do Judiciário. Na visão do procedimentalismo, que se relaciona com a vertente doutrinária brasileira chamada Democracia Deliberativa, a afirmação dos direitos é puramente democrática, de modo que cabe ao Poder Judiciário tão somente garantir “as regras do jogo" e não o protagonismo na concessão de políticas públicas.

Em contrapartida, os defensores do substancialismo entendem que a intervenção do Judiciário é legítima quando a Administração Pública não exerce seu papel de provedora do bem-social; quando atua com desvio de finalidade e/ou de poder; e quando descumpre os princípios constitucionais da Administração Pública. Nestes casos, tem-se o controle e a ação jurisdicional como um dever, por meio do qual o Poder Judiciário exerce a consolidação dos direitos fundamentais e cumpre o seu papel de guardião da Constituição, sobretudo do sistema democrático.

Outrossim, ao considerar que o Estado é um só e que os Poderes constituem e representam essa figura única do Estado, a "interferência" a que se refere é legítima, pois levase em consideração uma complementação de um Poder na atuação do outro para que os fins sejam devidamente atingidos. Cumpre salientar que os direitos fundamentais são habitualmente vilipendiados diante da atual conjuntura social. Uma sociedade que sofre com a ineficiente atuação dos agentes públicos e que ainda é atormentada pelo histórico da desigualdade social e exclusão dos grupos minoritários, uma postura contramajoritária se faz necessária.

Sob o respaldo do princípio da inafastabilidade da jurisdição, também conhecido como princípio fundamental do acesso à justiça, a atuação atípica do Poder Judiciário quando provocado e diante da inércia ou atuação ineficiente do Poder Executivo em executar as promessas constitucionais, se legitima. Sob essa perspectiva, o estudo que ora se descortina tem por escopo abordar a questão do controle e intervenção jurisdicional dos atos administrativos, mais especificamente das políticas públicas, quando há inobservância ou mitigação do princípio da eficiência pela Administração Pública, problematizando e se empenhando em responder se, no contexto social atual, tal participação do Poder Judiciário é legítima.

O trabalho adota o método de pesquisa dedutivo e utiliza a pesquisa bibliográfica como 
procedimento técnico, pautado, majoritariamente, na análise de artigos publicados em periódicos e também na consulta à legislação. No que tange à divisão estrutural, a pesquisa está dividida em três partes.

$\mathrm{Na}$ primeira parte, busca-se discorrer sobre a eficiência como um dos princípios constitucionais e gerais da Administração Pública, bem como apresentar o contexto social em que surgiu a necessidade de sua inserção no texto constitucional. Na segunda parte, tem-se o objetivo de trabalhar alguns aspectos do conceito do princípio da eficiência e de sua importância para a formulação e desemprenho dos atos administrativos, mais especificamente no que tange às políticas públicas. Finalmente, na terceira parte dedica-se a apresentar as hipóteses que legitimam o controle jurisdicional das políticas públicas no contexto social emergente.

\section{A eficiência como um princípio constitucional da administração pública}

A Administração Pública possui como encargo o desempenho do poder de gestão do Estado, por isso, dentre tantas atividades que possui e finalidades a alcançar, destaca-se como elementar: suprir as necessidades da coletividade para alcançar o bem-estar social. Contudo, como bem destacam_Ilton Garcia da Costa e Winnicius Pereira Goes (2016, p. 661) esse desempenho deve suceder "sem prender-se apenas à tirania do presente (do curto prazo) para atender às necessidades imediatas e as mediatas (do longo prazo)".

Neste cenário complexo e dinâmico acarretado pelo desenvolvimento acelerado das comunidades que introduzem inexoráveis mudanças no cotidiano, e, consequentemente, novos anseios sociais, os agentes públicos contam com algumas prerrogativas e possuem deveres imprescindíveis de modo a conduzir o serviço desempenhado da melhor forma possível. Os princípios gerais da Administração Púbica, elencados no art. 37, caput, da Constituição Federal de 1988 consistem em regras, que devem ser observadas pela Administração Pública direta e indireta de qualquer dos Poderes da União, dos Estados, do Distrito Federal e dos Municípios, para que os seus atos atinjam os objetivos com excelência.

Há vastidão de definições e conceitos na doutrina brasileira no que tange aos princípios. Para Robert Alexy (2008, p. 90) os princípios são “mandamentos de otimização”, ou seja, são regras que exigem que algo seja realizado "na maior medida possível dentro das possibilidades jurídicas e fáticas”. José Cretella Junior, por sua vez, diz que "princípios de uma ciência são as proposições básicas, fundamentais, típicas que condicionam todas as estruturações subsequentes. Princípios, neste sentido são os alicerces da ciência” (DI PIETRO, 2009, p. 62).

A Constituição Federal de 1988 consagra expressamente vários princípios da 
Administração Pública por todo o seu texto e, especificamente, em seu artigo 37, caput, estabelece os princípios gerais que devem orientar todos os atos da Administração Pública direta e indireta. São eles: legalidade, impessoalidade, moralidade, publicidade e eficiência.

O princípio da legalidade representa o vínculo do agir da Administração Pública à norma jurídica, em outras palavras, o agente público só pode atuar quando houver uma lei prévia permitindo. Desse modo, está adstrito aos mandamentos preexistentes da lei, sob pena de praticar ato ilegítimo e/ou ilegal. Faz-se oportuno destacar que a legalidade, como princípio que orienta os atos públicos, não coaduna com a legalidade geral do art. $5^{\circ}$, II, da Constituição Federal, o qual dispõe que ninguém será obrigado a fazer ou deixar de fazer alguma coisa senão em virtude de lei. Enquanto o princípio da legalidade da Administração Pública veda qualquer ato sem prévia permissão legal, a legalidade geral estabelece garantia ampla aos particulares de não restrição de sua liberdade senão pelo Parlamento.

O segundo princípio estabelecido no rol do art. 37, caput, da CF, é o da impessoalidade, o qual estabelece um dever de imparcialidade aos agentes públicos no desempenho de suas funções. Fernanda Marinela (2016, p. 89), diz que o referido princípio:

[...] pode ser analisado sob dois aspectos diferentes: primeiro, quanto ao dever de atendimento ao interesse público, tendo o administrador a obrigação de agir de forma impessoal, abstrata, genérica, protegendo sempre a coletividade; segundo, que a atividade administrativa exercida por um agente público seja imputada ao órgão ou entidade, e não ao próprio agente.

Atualmente, o princípio da impessoalidade se desmembra em quatro vertentes. A primeira delas refere-se ao tratamento impessoal. Cita-se como exemplo desta vertente os concursos públicos, que asseguram a isonomia no tratamento dos concorrentes. A segunda vertente relaciona-se ao ato de administrar de forma impessoal. A terceira refere-se à proibição da promoção pessoal relacionada ao uso de logomarca, símbolos, imagem e nomes pessoais de agente ou autoridade nas propagandas governamentais, visto que tais atos comprometem a noção de res publica. Por fim, a quarta vertente estabelece a irresponsabilidade pessoal do agente pela reparação de danos causados a terceiros no exercício regular da função administrativa, sendo tal encargo atribuído à pessoa jurídica estatal a que estiver ligado.

O terceiro princípio administrativo do rol do art. 37, caput, da CF é o da moralidade, que não se restringe apenas ao cumprimento da estrita legalidade por parte do agente público, mas estabelece que o desempenho de suas funções seja norteado pela ética, decoro, probidade, lealdade e boa-fé. O texto constitucional apresenta, em pelo menos duas oportunidades, este dever de observância da moralidade administrativa. Primeiro no art. $5^{\circ}$, LXXIII, quando autoriza a propositura de ação popular contra ato lesivo à moralidade administrativa. E ainda, 
no art. 85, V, quando define como crime de responsabilidade do Presidente da República os atos que atentam contra a probidade administrativa.

O princípio da publicidade, no que lhe concerne, engloba dois subprincípios: o da transparência e o da divulgação oficial. A publicidade ampla confere à sociedade o conhecimento da atuação administrativa através de publicações na imprensa oficial. Esse direito dos indivíduos ao livre acesso a informações possibilita que tomem ciência do que está ocorrendo no âmbito interno da Administração Pública e exerçam o direito de exigir melhorias dos serviços prestados.

Por fim, tem-se a eficiência, incluída, expressamente, como princípio geral da Administração Pública no rol do art. 37, caput, da CF por meio da Emenda Constitucional 19/1998. Embora o seu caráter de princípio geral tenha sido oficializado apenas no final da década de noventa, a eficiência já era mencionada nos artigos 74 , II e $144, \S 7^{\circ}$ do texto constitucional e considerada pela doutrina e jurisprudência como elemento imprescindível na atuação Administrativa Pública.

Para compreender melhor o motivo da necessidade da consagração do princípio da eficiência no texto constitucional, é necessário citar o contexto social que serviu como um dos estímulos ao poder constituinte derivado a emendar a CF em 1998. Antes de adentrar no marco histórico, faz-se importante citar Santos (2020, p. 39), que sucintamente apresenta as diferentes posturas tomadas pelo Estado no decorrer do tempo:

\footnotetext{
Desde o início da era moderna o mundo vem passando por diversas transformações. Nessa trajetória incessante, o Estado foi alterando sua roupagem e a maneira de se portar frente aos sérios problemas que afetam a sociedade. Na transição do Antigo Regime para o Liberalismo, o Estado adere uma postura abstencionista dando margem à livre economia capitalista e, consequentemente, aos dilemas resultantes. Mais adiante, com a eclosão dos direitos sociais positivos, o Estado deixa de se omitir e passa a tomar uma postura ativa como agente provedor do bem-estar social. Nesses moldes, o Estado de Direito representou uma importante evolução da trajetória política, social e econômica da sociedade moderna.
}

Contrariamente à postura abstencionista frente aos dilemas sociais tomada pelo Estado no período do Liberalismo, o período do Estado de Bem-estar Social, conhecido como Welfare State delineava uma figura de Estado Providência, de tudo para todos. A Constituição Federal de 1988, apresentou um rol de novas responsabilidades do Estado, aumentando substancialmente a sua estrutura e atuação. Em virtude disso, "este passou a enfrentar um encarecimento do custeio de servidores, de bens e serviços, além de um pontual aumento da ineficiência dos serviços públicos prestados." Cenário este, que desencadeou uma crise do Estado de bem-estar Social e "que resultou na proposta de reforma gerencial da Administração 
Pública." (SANTOS, 2020, p. 38)

Diante dessa crise, revelou-se a figura de um Estado ineficiente, incapaz de satisfazer os anseios da população. Um dos pontos da Reforma da Administração Pública foi justamente aumentar a eficiência dos serviços sociais oferecidos ou financiados pelo Estado. Alexandre de Moraes (2002, p. 317) explica que:

O princípio da eficiência é o que impõe à Administração Pública direta e indireta e a seus agentes a persecução do bem comum, por meio do exercício de suas competências de forma imparcial, neutra, transparente, participativa, eficaz, sem burocracia e sempre em busca da qualidade, primando pela adoção dos critérios legais e morais necessários para a melhor utilização possível dos recursos públicos, de maneira a evitar desperdícios e garantir uma maior rentabilidade social.

Agir com eficiência no âmbito da gestão pública é imprescindível para uma atuação apta a atender de maneira satisfatória os anseios da coletividade. Isto significa dizer que o administrador deve exercer suas funções da melhor maneira possível, sempre atento à moralidade, à transparência e à economicidade.

Importante frisar que, antes da reforma, o princípio da eficiência já existia implícito na Constituição, ao prever um sistema de controle interno com o fim de comprovar a legalidade e avaliar os resultados quanto à eficácia e eficiência da gestão orçamentária, financeira e patrimonial nos órgãos e entidades da Administração Federal. O Superior Tribunal de Justiça também reconhecia a existência desse princípio como um dos regentes da administração. (FLESCH, 2015, p. 215-216)

Para alcançar os fins que justificam sua existência e satisfazer as necessidades sociais, o Estado possui uma gama de incumbências de naturezas distintas. Para que tais tarefas sejam cumpridas com presteza, é fundamental a existência de algumas regras. Logo, os princípios supracitados possuem esse condão e necessitam de plena observância e obediência.

Faz-se importante mencionar que, além de princípio, a eficiência também pode ser entendida como finalidade e resultado. No mais, corresponde à observância de todos os outros princípios administrativos no desempenho das funções públicas. Valter Foleto Santin, dispõe que "a concretização do princípio da eficiência no texto constitucional torna mais claro o direito público subjetivo do cidadão e da coletividade à melhoria dos serviços públicos e da atuação da Administração Pública”. (SANTIN, 2013, p. 85)

Ao submeter-se a uma função pública, o agente deve estar ciente que não ocupará apenas um cargo. Como representante da Pessoa Jurídica quando no desemprenho de suas atividades estará contraindo um compromisso com a coletividade. Portanto, deve deixar os seus interesses pessoais de lado e atuar sob a égide da legalidade, do mesmo modo, deve agir com moralidade e eficiência, objetivando sempre o alcance do melhor resultado. Faz-se importante citar as 
palavras de Paes e Rodrigues (2012, p. 19):

Desta forma é possível se ter uma noção de qual o objetivo deste princípio, que seria atender a necessidade de seus administrados de forma mais rápida e segura através de técnicas cada vez mais modernas, realizando assim uma economia aos cofres públicos.

Agir com eficiência, portanto, significa desburocratizar. O que se traduz em ser célere, alcançar os objetivos desejados (pela sociedade) da melhor maneira possível, atingir o maior número de cidadãos e utilizar os meios que resultem no menor prejuízo possível aos cofres públicos. Além de observar todos os princípios que regem a Administração Pública e atuar da melhor maneira possível para atender as necessidades da sociedade conferindo primazia ao bem-estar multidimensional, ao agente público também cabe a tarefa do exame de custobenefício. Segundo Juarez Freitas (2015, p. 214) isso quer dizer que Administração Pública “[...] está obrigada a realizar avaliações de custos e benefícios abrangentes (econômicos e não econômicos), com a correspondente prestação de contas [...]".

Apesar de o presente artigo tratar da eficiência como um princípio geral da Administração Pública, é importante mencionar que para a consolidação de uma sociedade organizada, tal princípio também deve ser observado em todos os outros setores, principalmente, no que tange ao âmbito público geral, estendendo-se a sua necessária observância aos Poderes Judiciário e Legislativo.

Por derradeiro, constantemente, considera-se a eficiência como sinônimo de eficácia e efetividade. Embora foneticamente semelhantes, estes termos são distintos e referem-se a momentos específicos. Tal diferenciação é bem ressaltada por Marcelo Torres (2004, p. 175). Vejamos:

\footnotetext{
Eficácia: basicamente, a preocupação maior que o conceito revela se relaciona simplesmente com o atingimento dos objetivos desejados por determinada ação estatal, pouco se importando com os meios e mecanismos utilizados para atingir tais objetivos. Eficiência: aqui, mais importante que o simples alcance dos objetivos estabelecidos é deixar explícito como esses foram conseguidos. Existe claramente a preocupação com os mecanismos utilizados para obtenção do êxito da ação estatal, ou seja, é preciso buscar os meios mais econômicos e viáveis, utilizando a racionalidade econômica que busca maximizar os resultados e minimizar os custos, ou seja, fazer o melhor com menores custos, gastando com inteligência os recursos pagos pelo contribuinte.
}

Conforme o autor, os conceitos de eficácia e eficiência se diferenciam pelo fato de o primeiro corresponder ao mérito, ou melhor dizendo, ao alcance do objeto pretendido, não importando aqui quais foram as ações desenvolvidas ou os métodos utilizados para tanto. Já a eficiência corresponde ao cuidado com a escolha do caminho a ser percorrido. Relaciona-se com a preocupação à observância dos princípios e com a utilização dos meios mais viáveis, 
céleres e econômicos aos cofres públicos.

Caravantes e Bjur, no que lhe concerne, de maneira mais breve, diferenciam eficiência, eficácia e efetividade da seguinte forma:

\begin{abstract}
A eficiência verifica se um programa público foi executado de maneira mais competente e segundo a melhor relação custo/resultado; a eficácia, se os resultados previstos foram alcançados em termos de quantidade e qualidade; a efetividade, se o programa responde adequadamente às demandas, aos apoios e às necessidades da comunidade. (SANTIN, 2013, p. 88)
\end{abstract}

Assim, segundo os autores supracitados, os termos são avaliados da seguinte forma: a eficiência, investigando qual foi o caminho percorrido para se alcançar determinado fim; a eficácia, investigando se o objetivo pretendido foi alcançado; e a efetividade, avaliando se do objetivo alcançado surtiram efeitos positivos para a coletividade. Por fim, utilizando-se de uma linguagem menos técnica, autêntica e bastante esclarecedora, Santin (2013, p. 89), apresenta a sua distinção entre os termos:

Para uma comparação com o preparo de um bolo, a eficiência em sentido estrito seria a mão-de-obra, a estrutura (batedeira, talheres, forma, forno) e os ingredientes (farinha, ovos, leite); eficácia seria o produto pronto (bolo); efetividade, seria comer o bolo e sentir prazer (alimentar-se e satisfazer-se pelo sabor).

Diante do que foi abordado, infere-se que o princípio da eficiência foi consagrado no texto constitucional pela Emenda Constitucional 19/98 como um resultado da Reforma da Administração Pública ocorrida em virtude da crise do Estado de Bem-estar Social. Um dos objetivos da Reforma foi desafogar a máquina estatal e atribuir maior eficiência aos serviços prestados à coletividade. Ademais verificou-se que agir com eficiência envolve uma gama de ações que devem ser observadas pelos agentes públicos na consecução de atos mais sólidos e eficazes.

No capítulo seguinte, a discussão sobre o princípio da eficiência tomará um enfoque mais prático, considerando a sua importância para a formulação e concretização dos atos públicos, mais especificamente das políticas públicas.

\title{
2 A importância do princípio da eficiência no desenvolvimento de políticas públicas
}

Antes de mais nada, faz-se necessário compreender que Políticas Públicas consistem no conjunto de programas, atos e ações desenvolvidos direta ou indiretamente pelo Estado que visam assegurar determinado direito constitucionalmente preestabelecido, de forma difusa ou para determinado grupo. Nesse diapasão, Caroline Gomes de Mello e Ilton Garcia da Costa 
(2018, p. 306) oportunamente destacam que "o Estado tem a obrigação de assegurar a dignidade da pessoa humana, compensando as desigualdades sociais, por meio da implementação de políticas públicas, compreendidas como o principal instrumento para a concretização dos direitos sociais".

Para que as necessidades de uma sociedade sejam devidamente atendidas, é necessário que a realização de todos os atos seja feita com êxito e transparência, de modo a evitar medidas desnecessárias, excessos e, principalmente, atos ilegítimos e/ou ilegais.

Essa intervenção Estatal deve buscar o bem-estar social, podendo ser destinada a toda a coletividade ou a um grupo determinado de pessoas que dela careçam. As políticas públicas correspondem aos direitos constitucionais ou até mesmo a direitos reconhecidos pela sociedade. A criação dessas políticas é papel destinado ao governo, ou seja, ele delimita quais são os seguimentos que lhe convêm, como o social, o cultural, o étnico ou o econômico. (COSTA; CAMPIDELLI, 2016, p. 98)

Para a implementação de políticas públicas que sejam realmente eficazes, faz-se imprescindível a observância, pela Administração Pública, dos princípios gerais que lhe regem (legalidade, impessoalidade, moralidade, publicidade e eficiência), tanto no momento da formulação como no da execução. Conforme o capítulo anterior, um dos propósitos da EC 19/98 foi tornar a eficiência um dos princípios gerais da Administração Pública. Visto que, não basta que o ato seja legal, moral e impessoal, deve também, imprescindivelmente, ser eficiente.

\footnotetext{
Dessa forma, a EC n ${ }^{\circ}$ 19/98, seguindo os passos do direito comparado, no sentido de pretender garantir maior qualidade na atividade pública e na prestação dos serviços públicos, passou a proclamar que a Administração Pública direta, indireta ou fundacional, de qualquer dos Poderes da União, dos Estados, do Distrito Federal e dos Municípios, deverá obedecer, além dos tradicionais princípios de legalidade, impessoalidade, moralidade, publicidade, também ao princípio da eficiência. (MORAES, 2006, p. 22)
}

Isso quer dizer que, os agentes públicos devem utilizar o dinheiro público de maneira lícita e útil, capaz de proporcionar a satisfação das necessidades da população de forma célere e eficaz, sempre optando pelo meio mais rentável. Nas palavras de Maximiliano (2000): “A antítese da eficiência é o desperdício”. Assim, seja mediante execução direta, seja por delegação a particulares, através das formalidades legais, a Administração Pública deve buscar exercer suas incumbências sempre da melhor maneira e com atenção aos custos.

Nesse contexto, vale citar as palavras de Alexandre de Moraes (2006, p. 22):

O princípio da eficiência é o que impõe à Administração Pública direta e indireta e a seus agentes a persecução do bem comum, por meio do exercício de suas competências de forma imparcial, neutra, transparente, participativa, eficaz, sem burocracia e sempre em busca da qualidade, primando pela adoção dos critérios legais e morais necessários para a melhor utilização possível dos recursos públicos, de maneira a evitar desperdícios e garantir uma maior rentabilidade social. 
A estrutura social contemporânea carece de um modelo de gestão pública ético e transparente, que consiga adequar as necessidades da sociedade a uma visão estratégica a longo prazo. Isto consiste na base para uma boa governança, componente fundamental para se atingir uma sociedade justa e igualitária.

Uma boa governança no setor público compreende, dentre outros inúmeros requisitos, estratégias inteligentes, controle postos em prática para avaliar, direcionar e monitorar a atuação da gestão, bem como métodos eficientes para o desenvolvimento de políticas públicas eficazes que correspondam, de fato, às necessidades da população. Para Paulo Nogueira da Costa (2014, p. 153), "a participação; o respeito pelo Estado de Direito; a transparência; a resposivenes; a orientação para os consensos; a igualdade e a inclusividade; a eficácia e a eficiência; a accountability" são dimensões fundamentais para uma boa governança.

Para o alcance de maior sucesso da atuação pública através da implantação das políticas, existem alguns instrumentos aptos a colaborar na observância da eficiência. Cita-se como exemplo as formas de controle, tanto interno, realizado pela própria Administração Pública, como o externo, realizado por diferentes órgãos; os programas de qualidade e produtividade do serviço público; e, não menos importante, a participação ativa dos cidadãos no âmbito público.

O controle interno, está previsto nos artigos 31 (aplica-se aos municípios), 70 e 74 da Constituição de 1988. Entretanto, o seu fortalecimento se deu com a Lei de Responsabilidade Fiscal, a qual impôs uma organização mais acentuada aos administradores. Conceitua-se o controle interno como a fiscalização exercida por um órgão específico hierarquicamente superior dentro da mesma organização. Além de possibilitar a destituição ou correção de atos inapropriados e, assim, evitar erros e fraudes, tal controle objetiva preservar o interesse público e orientar o administrador na tomada de decisões.

No que concerne ao controle externo, a sua finalidade está relacionada ao desempenho de uma certa "vigilância exercida por outro órgão público e pela sociedade, dá-se no âmbito público pela atuação do Ministério Público [...] (SANTIN, 2013, p. 118). Numa sociedade em que prospera o regime democrático, este tipo de controle pode ter aparência de interferência, provocando reações adversas. Acerca dessa questão, Santin (2013, p. 117) estabelece:

\footnotetext{
Não se trata propriamente de diminuição da instituição nem de desconfiança ou suspeita. Ao contrário, o controle externo deve ser encarado como um reconhecimento do seu valor institucional e do seu poder social e principalmente um estímulo ao cumprimento dos princípios da legalidade, moralidade, impessoalidade, eficiência e igualdade para a melhoria dos trabalhos e até um fortalecimento institucional. (SANTIN, 2013, p. 117)
}

A atuação conjunta do controle interno, exercido no próprio órgão, e do controle 
externo, exercido por órgão alheio, auxilia no processo para o alcance de uma boa administração. Dessa forma, tanto o controle interno quanto o externo são essenciais para um legítimo desempenho das atividades da Administração Pública, visando garantir o atendimento das necessidades sociais de forma eficiente.

Estes meios de acompanhamento dos atos públicos possibilitam a fiscalização pelos cidadãos e a reclamação, por instrumentos próprios, quando a atuação administrativa incorrer em desvio de finalidade e/ou de poder ou, ainda, quando houver negligência ou ineficiência dos atos. Hely Lopes Meirelles (2002, p. 90) dispõe que:

[...] a Administração Pública deve sempre buscar aperfeiçoar a prestação dos serviços públicos, ou melhorando os que não estiverem satisfatórios, ou ainda, mantendo a qualidade dos serviços que estiverem suprindo as expectativas, tendo sempre como finalidade diminuir gastos, zelando pela qualidade nos serviços, e o bem comum.

Quando há observância do princípio da eficiência pela Administração Pública, os atos são devidamente conduzidos ao alcance dos objetivos pretendidos de forma legítima, rápida, eficaz e rentável aos cofres públicos. Como bem ressaltado por Juarez Freitas (2015, p. 200) "as escolhas administrativas serão legítimas se - e somente se - forem sistematicamente eficazes, sustentáveis, motivadas, proporcionais, imparciais, transparentes, e ativadoras da participação social, da moralidade e da plena responsabilidade.”

Assim sendo, ao ser introduzido no ordenamento jurídico como um dos princípios gerais da Administração Pública, o princípio da eficiência veio ratificar o que, na verdade, a coletividade sempre esperou do Poder Público. Quanto ao desempenho das atividades públicas, Ilton Garcia da Costa e Winnicius Pereira Góes (2016, p. 661) salientam que "diante das diferentes demandas, ao Estado e ao administrador público resta encontrar o melhor caminho, de preferência, aquele que o conduza à humanização político-administrativa."

A importância do princípio da eficiência é inestimável, visto que a prestação do serviço público legítimo, célere e de qualidade é direito dos cidadãos e dever do Estado social e democrático, assegurado pela Constituição Federal. Entretanto, diante da postura omissa ou ineficiente da Administração Pública quanto às necessidades sociais, muito se discute acerca da legitimidade da interferência do Poder Judiciário nas políticas públicas.

\section{A (i)legitimidade do controle jurisdicional das políticas públicas}

O controle jurisdicional exercido sobre os atos administrativos é majoritariamente aceito nos casos de ilegalidade, imoralidade e pessoalidade visto que os aludidos princípios 
administrativos estão expressos na Constituição por serem considerados imprescindíveis à elaboração e execução dos atos públicos. De forma congênere, após ser consagrada no texto constitucional como o quinto princípio geral administrativo, a eficiência também passou a ser indispensável para a formulação e execução de todos os atos da Administração Pública.

Santin (2013, p. 24) defende que "as próprias políticas públicas devem ser analisadas pelos ângulos de todos os princípios constitucionais, não apenas da legalidade.” Isso quer dizer que a interferência do Poder Judiciário nos atos administrativos desempenhados sem a observância do princípio da eficiência é legítima da mesma forma quando não houver a observância dos demais princípios administrativos. O mesmo autor (SANTIN, 2013, p. 24) dispõe ainda que:

Não tem sentido lógico e jurídico o constituinte inserir outros princípios no campo da
Administração Pública, além da legalidade, e sua utilização ou controle judicial ficar
restrito apenas a um dos princípios, a legalidade, porque o Estado Democrático de
Direito pauta-se pelo seguimento ao direito, não apenas uma das suas facetas, a
legalidade.

Embora essa questão do controle jurisdicional seja desafiadora e complexa dando margem a inúmeros questionamentos sobre sua legitimidade, sob o enfoque Neoconstitucionalista dos princípios e direitos fundamentais é absolutamente necessário tal intervenção para que haja a concretização do Estado Social e Democrático de Direito. Verificase através do art. $5^{\circ}, \mathrm{XXXV}$, que a própria Constituição Federal concedeu maior força ao controle jurisdicional incidente sobre a atividade administrativa ao expressar que a apreciação do Judiciário não se limita às lesões de direito, mas abrange também a mera ameaça.

Ademais, o art. $5^{\circ}, \mathrm{XXXV}$, do texto constitucional declara que a lei não excluirá da apreciação do Poder Judiciário lesão ou ameaça a direito, enfatizando, pois, a admissão do conflito pelo Judiciário através do direito de acesso à justiça (ou da tutela jurisdicional). O ponto questionado, portanto, não é se pode ou não haver controle jurisdicional, dado que a própria Constituição Federal de 1988 já esclarece, mas qual conteúdo pode ser objeto de apreciação pelo Poder Judiciário e quais os limites impostos a essa interferência.

Nessa perspectiva, Marques Neto (2010) entende que:

O controle da Administração não se presta apenas para evitar o desvio de bens ou
recursos públicos. O controle deve envolver também a verificação de que o poder
atribuído ao Estado está sendo manejado eficientemente para cumprir as finalidades
que justificam e legitimam a sua atribuição ao agente público ou se o sacrifício de
direitos individuais inerentes à ação estatal está correspondente ao proveito efetivo
auferível pela coletividade.

A possibilidade de se obter no Judiciário o que foi negligenciado ou prestado de maneira ineficiente pela Administração Pública, é um direito fundamental do cidadão assegurado pelo 
art. 5 $5^{\circ}, \mathrm{XXXV}$, da CF. Dessa forma, exercer o controle dos atos administrativos eivados de algum vício que prejudique o interesse social parece razoavelmente um ato legítimo, e o contrário, por assim dizer, ilegítimo.

Odete Medauar (2011, p. 398), apropriadamente, relembra que a Declaração dos Direitos do Homem e do Cidadão de 1789 já continha em seu art. 15 o seguinte preceito: "A sociedade tem o direito de pedir conta, a todo agente público, quanto à sua administração". De acordo com Gnata (2011, p. 186) “Admite-se, portanto, a possibilidade de investigação do fundamento dos atos estatais pelo Poder Judiciário, ou seja, a legitimidade jurisdicional para o controle de políticas públicas".

Com a evolução da sociedade moderna as relações sociais foram se modificando e se tornando cada vez mais complexas, caminhando para um constante questionamento das políticas públicas adotadas pelos representantes populares no exercício de suas funções. Neste cenário, o Poder Judiciário é frequentemente acionado para se manifestar sobre os direitos existentes nas controvérsias políticas, adotando uma visão democrática do Estado de Direito.

\begin{abstract}
Assim, se por um lado não cabe ao Poder Judiciário moldar a Administração Pública discricionariamente, por outro lado, a constitucionalização das normas básicas do Direito Administrativo permite ao Judiciário impedir que o Executivo molde a Administração Pública em discordância a seus princípios e preceitos constitucionais básicos, pois a finalidade do controle de constitucionalidade é retirar do ordenamento jurídico lei, ato normativo ou, nos casos concretos, atos administrativos incompatíveis com a ordem constitucional, constituindo-se, pois, uma finalidade de legislador negativo do STF, nunca de legislador positivo. (MORAES, 2006, p. 15)
\end{abstract}

Reconhecer a legitimidade do controle jurisdicional dos atos administrativos ineficientes, não significa ser condescendente à teoria da não deferência entre os Poderes - o ponto da presente discussão não é esse -, mas ter a consciência de que tal interferência consiste numa medida que aumenta a possibilidade de concretização dos direitos constitucionalmente previstos. A rigor, observa-se um certo egoísmo por parte dos agentes públicos, sejam eleitos ou não, por pensarem que o controle jurisdicional está relacionado à circunstância de quem “proclama a palavra final”. Uma ideologia certamente incoerente, pois o cerne da discussão não é o ego dos agentes da Administração Pública ou dos Magistrados, mas sim a concretização dos direitos fundamentais consagrados na Constituição Federal.

Quanto ao necessário controle jurisdicional dos atos da Administração Pública, Alexandre de Moraes (2006, p. 15), oportunamente, esclarece que a legitimidade dessa interferência é validada pela violação do princípio da eficiência: 


\begin{abstract}
Não será o juiz, portanto, quem planejará e executará a utilização dos recursos e a prestação dos serviços públicos à Sociedade, porém, poderá controlar o ato administrativo que determinou a ineficiente utilização do dinheiro público ou a prestação de serviços inócuos, anulando-os e responsabilizando o agente político que, no exercício de suas funções, desrespeitou o princípio da eficiência, expressamente previsto em nosso texto constitucional.
\end{abstract}

Diante da falta de implantação de políticas públicas eficazes ou, até mesmo, diante da violação de direitos fundamentais em virtude da execução de políticas inapropriadas e ineficientes, não se pode negar a necessidade de interferência do Poder Judiciário, num exercício complementar. Agora, faz-se oportuno citar o pensamento de Juarez Freitas (2015, p. 200), de que o direito fundamental à boa administração está, indiscutivelmente, ligado ao controle dos atos administrativos. Entretanto, este pensamento enfrenta hoje os seguintes argumentos adversos:

Em primeiro lugar, observa-se a crença infundada de que as políticas públicas pertenceriam ao reino da discricionariedade insindicável, como se as escolhas políticas (e, por vezes, as omissões), embora manifestamente viciadas, não fossem catalogáveis como inconstitucionais. Erro típico da mentalidade refratária aos contrapoderes de controle. Constata-se, em segundo lugar, a proposição, não menos equivocada, de que a separação de poderes representaria autêntica carta branca para os gestores públicos, os quais apenas seriam controláveis pelas urnas, no tocante às escolhas feitas, como se a higidez das prioridades concretamente adotadas fosse matéria reservada ao processo eleitoral, cujas distorções de financiamento e de ordem cognitiva conspiram, frequentes vezes, contra o cerne da Constituição. Erro característico dos que consideram legítimo e juridicamente seguro apenas aquilo que for produzido por legisladores e governantes eleitos, numa concepção demasiado acanhada do processo de deliberação democrática.

Outro argumento utilizado pelos oponentes do controle jurisdicional das políticas públicas refere-se à indeterminação do conceito de eficiência, que seria empecilho para sua correta definição e, consequentemente, para a imposição de limites à intervenção do Poder Judiciário. Contudo, deve-se considerar que a eficiência administrativa não é mais nem menos abstrata que os demais princípios da Administração Pública, pois até mesmo o princípio da legalidade é questão controvertida na doutrina.

Acerca desse argumento da impossibilidade do controle jurisdicional das políticas públicas em decorrência da indefinição do conceito de eficiência, Santin (2013, p. 24) apresenta a sua posição ao defender que "pouco importa que o princípio da moralidade, da impessoalidade e da eficiência sejam permeados por conceitos indeterminados e exijam uma dose maior de atenção e estudo para a verificação do seu desatendimento". Ao deparar-se com a indefinição de algum termo ou até mesmo de um princípio deve-se recorrer à hermenêutica para o estudo e realização da interpretação mais razoável possível de cada caso. Incumbência esta, atribuída aos intérpretes da Constituição Federal e guardiões dos direitos fundamentais.

Para o alcance da interpretação mais justa e razoável, devem utilizar, além dos métodos 
hermenêuticos de interpretação considerados contemporaneamente e dos postulados, dois princípios indispensáveis: a razoabilidade e a proporcionalidade. A razoabilidade consubstanciada na qualidade do que é razoável, procura determinar os limites possíveis, atingíveis e aceitáveis socialmente. Por conseguinte, a proporcionalidade está relacionada intimamente à prudência, sensatez e bom senso, evitando que medidas absurdas e incoerentes sejam adotadas. A obrigatoriedade de observância destes dois princípios pelo Poder Judiciário, evita "que o processo judicial e as decisões e comandos respectivos ponham abaixo todo o trabalho e planejamento dos órgãos executivos, encarregados da formulação e execução das políticas públicas”. (SANTIN, 2013, p.143)

Finalmente, vale ressaltar ainda que "a decisão judicial deverá estar adaptada e adequada à realidade social e governamental, determinando metas e tarefas factíveis, em consonância com as necessidades públicas e as condições orçamentárias e dos cofres públicos." (SANTIN, 2013, p. 146). É necessário ponderação entre as circunstâncias fáticas e jurídicas existentes.

\section{Considerações finais}

Com a Emenda Constitucional 19/98, a eficiência passou a integrar, expressamente, o rol dos princípios gerais da Administração Pública. Dessa forma, assim como a legalidade, impessoalidade, moralidade e publicidade, a eficiência também deve ser observada, na mesma medida, quando do desenvolvimento de todos os atos públicos. Agir com eficiência significa que o agente público deve atuar de maneira lícita, célere e eficaz, atingindo o maior número possível de cidadãos com seu ato e de forma que não comprometa demasiadamente os cofres públicos. Em outras palavras, deve atuar de maneira transparente e utilizar devidamente o dinheiro público para suprir os anseios da sociedade com eficácia.

Sob a ótica da Teoria da Separação dos Poderes, o controle jurisdicional é ilegítimo, visto que cada Poder tem sua função e seu espaço de atuação. Entretanto, ao concluir que o Estado é um só e que os Poderes constituem e representam essa figura única, tal interferência se legitima, pois, considera-se como uma complementação exercida por um Poder na atuação do outro para que fins maiores sejam atingidos.

É possível apontar quatro pontos que legitimam o controle jurisdicional das políticas públicas: 1) A provocação da tutela jurisdicional, assegurada pela Constituição Federal em seu art. $5^{\circ}, \mathrm{XXXV}$, por quem se encontre em situação desfavorável, de comprometimento de direitos em virtude da negligência ou ineficiência da Administração Pública; 2) A questão da má gestão, da ineficiência da Administração (que inclui a inobservância dos princípios 
administrativo e o uso indevido do dinheiro público); 3) Os pedidos do MP (no exercício do controle externo) para a consagração dos direitos difusos e coletivos; 4) O caráter de guardião da Constituição (principalmente dos direitos fundamentais) atribuído pela própria CF/1988 ao Poder Judiciário, que, em análise extensiva, seria de guardião do sistema democrático.

Da análise realizada pela pesquisa, infere-se que o controle jurisdicional das políticas públicas é uma questão que gera bastante repercussão doutrinária e jurisprudencial. As discussões existentes entre os apoiadores e os que são contrários à prática de interferência do Poder Judiciário estão longe de serem pacificadas. Contudo, há que se colocar na balança o aval dado pela CF/1988 ao Poder Judiciário, que embora seja contramajoritário, é constitucionalista. E isso não quer dizer que a Constituição seja antidemocrática, e sim que ela visa proteger a verdadeira democracia, os valores constitucionais.

\section{REFERÊNCIAS}

ALEXY, Robert. Teoria dos direitos fundamentais. 5. ed. São Paulo: Malheiros, 2008.

COSTA, Ilton Garcia; GONÇALVES, Aline M. Da Sociedade Antiga à Sociedade Politica e a Funcionalidade do Direito. Nomos (Fortaleza), v. 36, p. 205-224, 2016. Disponível em: http://www.periodicos.ufc.br/nomos/article/view/1766/4561. Acesso em: 03 nov. 2021.

COSTA, Ilton Garcia; CAMPIDELLI, Laisa F. A Diminuição da Extrema Pobreza, baseada em Políticas Públicas Eficazes e Garantia do Minimo Existencial. In: COSTA, Ilton Garcia da; CACHICHI, Rogerio Cangussu Dantas; LEÃO JUNIOR, Teofilo Marcelo de Arêa (org.). Paz, Constituição e Políticas Públicas, v. II. Curitiba: Instituto Memória, 2016. p. 85-103.

COSTA, Ilton Garcia; GOES, Winnicius Pereira. A Diretiva 2014/24/UE como Guia de Contratualizações Sustentáveis de Políticas Públicas Sociais. Novos Estudos Jurídicos (Online), v. 21, p. 656-690, 2016. Disponível em: https://doi.org/10.14210/nej.v21n2.p656690. Acesso em: 03 nov. 2021.

COSTA, Paulo Nogueira da. O Tribunal de Contas e a boa governança: contributo para uma reforma do controle financeiro externo em Portugal. Coimbra: Coimbra Editora, 2014.

DI PIETRO, Maria Sylvia Zanella. Direito administrativo. 22. ed. São Paulo: Atlas, 2009.

FLESCH, Carla Machado. A submissão da Administração Pública ao princípio da eficiência visando à satisfatória consecução de seus fins. Boletim Científico ESMPU, Brasília, a. 14 n. 45, p. 211-238, jul./dez. 2015. Disponível em:

file:///C:/Users/Usuario/Downloads/6.\%20A\%20submissao\%20da\%20Administracao\%20Pub lica\%20ao\%20principio\%20da\%20eficiencia\%20(2).pdf. Acesso em: 07 jun. 2021.

FREITAS, Juarez. As políticas públicas e o direito fundamental à boa administração. Revista do programa de Pós-graduação em Direito da UFC. v. 35.1, jan./jun. 2015. Disponível em: 
http://repositorio.pucrs.br/dspace/bitstream/10923/11494/2/As_politicas_publicas_e_o_direito _fundamental_a_boa_administracao.pdf. Acesso em: 22 jun. 2021.

GNATA, Noa Piatã Bassfeld. Crítica aos limites do controle jurisdicional de políticas públicas em direitos sociais. Espaço Jurídico Joaçaba, v. 12, n. 2, p. 181-196, jul./dez. 2011. Disponível em:

http://www.mpdft.mp.br/saude/images/judicializacao/Critica_limites_controle_jurisdicional.p df. Acesso em: 22 jun. 2021.

MARINELA, Fernanda. Direito administrativo. 10. ed. São Paulo: Saraiva, 2016.

MARQUES NETO, Floriano de Azevedo. Os grandes desafios do controle da Administração Pública. Fórum de Contratação e Gestão Pública - FCGP. Belo Horizonte, 2010.

Disponível em: http://www.editoraforum.com.br/wp-content/uploads/2016/10/desafioscontrole.pdf. Acesso em: 10 jun. 2021.

MAXIMIANO, A. C. A. Introdução à Administração. 5. ed. São Paulo: Atlas, 2000.

MEDAUAR, Odete. Direito administrativo moderno. 15. ed. São Paulo: Revista dos Tribunais, 2011.

MEIRELLES, Hely Lopes. Direito administrativo brasileiro. 27. ed. São Paulo: Malheiros, 2002.

MELLO, Caroline G.; COSTA, Ilton Garcia da. O controle das políticas públicas, Ministério Público e Tribunal de Contas. In: SARRETA, Cátia Rejane Liczbinski; MARCO, Cristhian Magnus de; XIMENES, Julia Maurmann (org.). Direitos sociais e políticas públicas.

Florianópolis: Conpedi, v. 1, p. 305-325, 2018. Disponível em:

http://site.conpedi.org.br/publicacoes/34q12098/s8787c81/B7M5vEX30Ori9Qnx.pdf. Acesso em: 03 nov. 2021.

MORAES, Alexandre de. Princípio da Eficiência e Controle Jurisdicional dos Atos Administrativos Discricionários. Revista de Direito Administrativo - FGV, v. 43, 2006. DOI: https://doi.org/10.12660/rda.v243.2006.42538. Disponível em:

https://bibliotecadigital.fgv.br/ojs/index.php/rda/article/view/42538. Acesso em: 10 jun. 2021.

MORAES, Alexandre de. Direito constitucional. São Paulo: Atlas, 2002.

PAES, Alberto de Moraes Papaléo; RODRIGUES, Aline Cardoso. O princípio da eficiência administrativa e a responsabilidade política do servidor público. Argumenta - UENP Jacarezinho, n. 17, p. 11-38, 2012. Disponível em: http://seer.uenp.edu.br/index.php/argumenta/article/view/231. Acesso em: 10 jun. 2021.

SANTIN, Valter Foleto. Controle judicial da segurança pública: eficiência na prevenção e repressão aocrime. 2. ed. São Paulo: Verbatim, 2013.

SANTOS, Ana Flávia Coelho dos. A Sociedade Civil Organizada na Desconstrução da Exclusão Social Através da Solidariedade: Dilemas e Perspectivas. 2020. 109 f. Dissertação de Mestrado - Programa de Pós-Graduação Stricto Sensu em Ciência Jurídica Universidade Estadual do Norte do Paraná. Disponível em: https://uenp.edu.br/doc- 
propg/pos-graduacao/stricto-sensu-mestrado-e-doutorado/pos-graduacao-direito/teses-edissertacoes/dissertacoes-defendidas-1/18158-ana-flavia-coelho-dos-santos/file. Acesso em: 03 nov. 2021.

TORRES, Marcelo Douglas de Figueiredo. Estado, democracia e administração pública no Brasil. Rio de Janeiro: Editora FGV, 2004. 